NBER WORKING PAPER SERIES DYNAMIC ASPECTS OF CHILDREN'S HEALTH,
INTELLECTUAL DEVELOPMENT,
AND FAMILY ECONOMIC STATUS

Robert A. Shakotko

Working Paper No. $\underline{451}$

NATIONAL BUREAU OF ECONOMIC RESEARCH

1050 Massachusetts Avenue

Cambridge MA 02138

February 1980

Research for this paper was supported by a grant from the Robert Wood Johnson Foundation to the National Bureau of Economic Research. I am indebted to Ann Colle for excellent research assistance, and to Anthony Cassese, Michael Grossman, Lee Lillard, and Robert Moffitt for valuable comments and suggestions. The research reported here is part of the NBER's research program in Health Economics. Any opinions expressed are those of the author and not those of the National Bureau of Economic Research. 


\section{Dynamic Aspects of Children's Health, Intellectual Development, and Family Economic Status}

\section{ABSTRACT}

This paper is an empirical investigation of childhood and adolescent health and cognitive development as determined by family economic variables. The model proposed recognizes that these processes may be jointly dependent, and may in part be determined by common unobserved factors; these factors may also be correleted with the observed family economic variables. A two-factor model is estimated using panel data, and the results indicate that when such factors are taken account of, family income is estimated to have no significant influence on health and cognitive development, but parents' education a strong positive influence.

Robert A. Shakotko Department of Economics Columbia University New York, New York 10027

(212) $280-2449$

Natioan1 Bureau of Economic Research 15-19 West 4th Street, 8th Floor Washington Square New York, New York 10012

(212) $598-3439$ 
The relationships between an individual's adult health and various economic variables have been examined cmpirically in a nunter of recent studies (Grossman and Eenham, 1974; Grossman, 1976; Lce, 1979; Shakotko, 1979). They stem from the idea that one's state of health is at least partly endogenous, reflecting one's stock of lealth capital, whose accumulation is determined to some extent by ecoromic and educational factors (Grossman, 1972). In turn, these cconomic and educational variables may themselves be partly determined by health. Investigators have also recognized that an individual's lifetime cconomic and physical well-being is due in large measure to conditions present or acquired during childhood. Educational success, for example, which is a significant determinant of adult carnings, may be partly determined by the individual's cognitive development and physical health as a child. Poor adult health, and its consequent economic hardship, may arise in many instances from poor hcalth during childhood or adolescence. 1 Given this link between life-cycle behavior and childhood conditions, it is important to understand the determinants of childhood development.

This paper is an empirical investigation of the determinants of childhood and adolescent health and cognitive development. The main feature of this investigation is that it draws together into one estimable empirical model three classes of postulated determinants of early health and coenitive development, and estimates their contritutions simultaneously. In this sense, the model is superior to previous studies which have analysed these determinants on a linited 
and pieccreal tasis. The mocel talics explicit account of the possitility tiat indivicual-specific unotserved factors jointly cetermine health and cognitive development, and recognizes tiat these factors may themselves be related to other ofserved determinants. The emphasis is on a two-factor nodel, where all of tie health, cognitive development, and lackground economic variables serve as indicators of the unobserved factors. The model is estimated with panel data for approximately $1400 \mathrm{children.}$

Three main results cmerge from the estimates of this nicdel. First, systematic unobserved factors are found to play a significant role in the determination of both health and cognitive developrient. These effects are relatively stronger in the equations determining cornitive development. Second, parents' education is found to te a positive contributor to toth processes, but family income is observed to have no significant effect. Third, a favorable history of early childiood achicvenient is found to have a small positive effect on future liealth, but poor early health has little effect on cognitive development. In fact, there is some evidence that poor health influences cognitive development positively:

The rest of the paper is organized as follows. Section I outlines the tasic model both theoretically and empirically. In Section 11, there is a brief discussion of the data. In section III, the estimates of the model are presented. These are compared to estimates of a model with no factor structure in terms of both effects of different variables and predictive power. 
I. An Analytic Framcwork

Thrce classes of variables which have teen widely proposed as deteminants of children's development might be latelled "nurture", "mature", and "history." While these are broad classifications, and perhaps at times misleading or inappropriate, trey serve well to indicate the dimensions of the analysis. In Eeneral, nurture refers to the impact of discretionary (or interventionary) telavior on the part of the household which affects children's development. Economic models of tousetiold production have hypothesized that this discretionary behavior is manifested in the form of $t$ ine and income investments in children. ${ }^{2}$ While it is difficult to measure these these investments directly, it is argued that the efficiency and sinitude of the investments are determined to a large extent by parents' education and family income.

The "nature" explanation of childhood development centers on those factors which are predetermined and therefore not controllable by the household. In medical literature, this effect is often labelled predisposition to certain health conditions. In terms of cognitive development, "nature" explanations are commonly associated with arguments for innate abilities and 10 inheritability. ${ }^{3}$ It is, hovever, important to point out that at the margin the distinction between nurture and nature effects is not totally resolved even conceptually. These effects outlined above relate to prysical predispositions. Eut it is not clear, however, where behavioral predispositions which cannot be explained by ecoriomic or educational factors should be accounted. 
Inclusion of "history" as a determinant of health and cornitive development reflects the recoenition that these procossos may be structurally related through time, and that a particular cvent can cvent being the collection of health and cornitive development outcomes at a point in time) may be due in some measure to tle occunence of a prior event. Stated alternatively, even controlling for nurture and nature inputs into dcvelopmental processes, observed outcomes may not be temporaliy independent. For example, some liealth conditions tend to be persistent, such that poor health at birth or tle acquistion of certain conditions in early childhood may explain the presence of these or other conditions later in the individual's i ife, quite aside from intervening or preceding nature and nurture influences. Also, children who develop intellectual skills early may be able to use these early abilities to acouire greater proficiency in other aspects of cognitive development. It is important to point out that these history effects need not be conceptually restricted to operate in univariate fashions. Indeed, it is conceivable that aspects of health and cognitive development are intercependent, whereby, for example, poor early health could impede subsequent cognitive development and below average levels of cognitive development could interfere with the child's ability to maintain good health. 4

While it is likely that the child's history of health and cognitive development is itself a function of varicus nurture and nature variables, controlling for the history of these processes will yield estimates of the structural links between different 
aspects of health and cognitive development and also more precise estimates of the effects of discretionary betavior as it is affected by parents' education and family income. These structural links usually cannot be identified in cross-section formulations becalise of the lack of identifying restrictions provided by the underlying theory. Voreover, modeliing these processes whereby past values of health and cognitive development are explicitly controlled for conforms more closely to classical experimental analysis. Typically, in laboratory experiments, assessment of an action's efficacy is made by observing the initial state, administering a measured "dosase", and then observing the final state, all in an effort to determine if and to what extent the procedure had any impact. Different aspects of the Sitial state and the intervening dosage are then related to the otserved final outcome in an attempt to explain the structure of a process. In the absence of a laboratory, the same conceptual framework can be applied to the analysis of children's development by otserving a time series for a number of individuals. By treating a particular child's history as a comparative benctimark, one can identify temporal interdependence between processes and perlieps more accurately measure the contributions of other variatles to favorable or unfavorable outcomes.

In stiort, a completely specified model of children's development must be capable of incorporating all of the ahove as potential sources of observed variation in measures of health and cognitive development, as well as recoenizing the possible relationships anong the three classes of determinants themselves. It is well-known that 
Lhis latter point is a particularly troublesome statistical issue, since "natule" väriables are in practice unotserved, and even in principle may not be observatle or measurable. In the alsence of information on this potential determinant, variance in obscrvod outcomes may be incorrectly ascribed to otfer of served deterininats, especially since it is comonly argued that "nature" is correlated with both history and rurture.

An analogy between this problem and the familiar ability-bias problem in estimates of earnings functions is apparent. If ability is correlated with the observed level of completed schooling, and if both influence earnings, then an estimated earnings function which disregards ability will yield schooling coefficients which are biased ufruis. As a solution to this specification problem when atility is not olserved, Chamberlain $(1977,1978)$ has proposed joint modelling of equations for all observed variables which may be indicators of an unobserved factor or factors. Given a sufficient set of identifying restrictions, the parameters of such equations, and the distributional parameters of the unobserved factor(s), can be estimated using a random effects procedure.

A linear formulation of such a model may be written

$$
B y_{1}=\Lambda f_{1}+\varepsilon_{1},
$$

where $y_{1}$ is an $n \times 1$ column vector of observed variables including measures of current and past health and cognitive development, parents' education, and family income, where $f_{1}$ is a kxl vectcr of exorenous individual-or family-specific urotserved 
factors, and where $\varepsilon_{i}$ is a vector of stectastic disturtances, uncorrelated with $f_{f}$. The index $i$ indicates the $i$-th individual. Derioting the covariance matrices of $f_{1}$ and $\varepsilon_{1}$ by $\Sigma_{f}$ and $\Sigma_{\varepsilon}$ respectively, and premultiplying (1) by $B^{-1}$ yiclds

$$
y_{1}=B^{-1} \Lambda f_{1}+B^{-1} \varepsilon_{1}
$$

and

$$
\Sigma_{y}=B^{-1} \Lambda \Sigma_{f} \Lambda^{\prime}\left(B^{-1}\right)^{\prime}+B^{-1} \Sigma_{E}\left(B^{-1}\right)^{\prime},
$$

where $\Sigma_{y}$ is the nxn covariance matrix of $y_{1}$. Assuming $f_{1}$ and $\varepsilon_{1}$ are distributed normally, the log-likelihood function for the $i-t h$ individual is

$$
L_{1}\left(B, \Lambda, \Sigma_{f}, \Sigma_{\varepsilon}\right)^{-}=-1 / 2 \log \left|\Sigma_{y}\right|-1 / 2\left(y_{1}-E\left(y_{1}\right)\right)^{\prime} \Sigma_{y}^{-1}\left(y_{1}-E\left(y_{1}\right)\right) .
$$

and if the vectors $f$ and $\varepsilon$ are uncorrelated across individuals, then the joint likelihood function for a sample of $\mathrm{N}$ individuals can be written

$$
L\left(B, \Lambda, \Sigma_{f}, \Sigma_{\varepsilon}\right)=-N / 2 \log \left|\Sigma_{y}\right|-N / 2 \operatorname{tr}\left(S \Sigma_{y}^{-1}\right),
$$

where $S$ is the sample covariance matrix of $y$, and where $\Sigma_{y}$ is given by (2). The remainder of the paper presents estimates of $B$, $1, \Sigma_{f}$, and $\Sigma_{E}$ obtained by maximizing (4) under various restrictions. One cautionary word should be expressed at this point. While the vector structural equation (1) takes explicit account of unotserved variables, and while most discussions of unotserved variatiles in the context of children's development have centered on genetic factors as 
toing the chicf component of "nature", unobserved variatles by their very nature have unobserved names. The primary interest in this mimer is not so much in assigning names and interpretations to the estinatod factor structure, but rather in estimating the relaticriships airong health, cosnitive development, and family backsround variatics once the possibility of common determining factors is taken account of.

\section{The Data}

The model outlined in the preceding section is estinated using data from Cycles II and III of the U.S. Health Examination Survey (HES). Both sections of the survey collected extensive data on the current health and health histories for a nationally representative sample of children: Cycle II surveyed children aged 6 to 11 in the early 1960s, and Cycle 111 surveyed adolescents aged 12 to 17 in the late 1960s. In each case, data include results from a plysician's examination, scores from different tests, and surveys of the child's parents and school.

Approximately 2200 of the children in Cycle 11 were re-surveyed in cycle 111 . Of these, a final sample of 1434 was selected for andysis. Because of cross-section evidence that the health and cognitive development processes differ significantly for blacks, they were not included in this sample, nor were observations with missing data. It should be noted that there is considerably more age horiogeneity in this longitudinal subset than in the overall cross-section surveys: in Cycle 111,99 percent of the adoloscents in the longitudinal sutset were aged 12 to 15 . The re-survey interval 
of this sulsample averages 42 months, with 70 percent of the saliple intervals falling between 36 and 48 months. While it is difficult to assess the effects of even this limited are and intcrval hetcrogeneity on the estimates of the model, it is unlikely that any of the main results will be substantially affected. Using the same data, Shatotko, Edwards, and crossman (1980) found tiat controiling for these variables did not in most cases contrirute significantiy to their model's explanatory power. In any case, both measures of cognitive development and one measure of health used in this analysis are age-adjusted.

Specifically, the analysis examines the relationships among thirteen variables. The primary focus is on two measures of cognitive development and two measures of health: (1) the bechsler Intelligence Scale for Children (WISC); (2) the Wide Ranse Achievement Test (WRAT); (3) the age- and sex-adjusted periodontal index, which is a measure of oral health (APERI); (4) the diagnosis of a "significant atnormality" by the examining physician ( $A B N$ ). Each of these four variables is reported in cycles 11 and 111 , and to distinguish the two measures of each variable, the post-script "1" is used to denote a Cycle II value and " 2 " to denote a Cycle $\| 1$ value. "ISC, URAT, and APERI are all continuous variables, and and $A B N$ is a dichotomous variable taking the value of one if an abnomality was found and zero otherwise.

other health measures included to control for history effects are duminy variatles indicating a farental assessment of poor beath for the clild during the first year after birth (FYPH) and a duminiy 
indicating if the child's birth weight was 2000 bramis or lcss (LIGHT). Family lackground variables used are fanily inconc (riallac), fatler's education in years (FATHED), and riother's ciucation (liollieD). The sample means and standard deviations of these variables ale reported in Table 1 .

The particular measures of health and cognitive develoriant included in the analysis were chosen to ensure some tevel of Benerality while at the same time acknowledging that both health and cognitive development have different components. For example, lisc is designed to measure general cognitive aptitudes, while WRAT mcasures more specific acquired skills. The abnornal diaznosis indicator (AEN) is an objective measure of the presence of a condition which affects current physical activities, or could affect future activities. 8 The periodontal index (APERI) was used tecause it is perhaps the most sensitive to differential levels of family health investment, and hence may be best indicative of proventive medical care.

Without doubt, this analysis is restrictive, not only in its consideration of relatively few measures of health and cognitive development, but also in its limited consideration of other observable variables that may affect developmental processes. A more detailed examination of other variables was conducted by Edwards and Grossman (1978) and Shakotko, Edwards, and Grossman (1980); these studics have shown that most other variables contribute relatively little to explaining the variance of the measurcs analysed here. lioreover, it is likely that consideration of lareer and more complex 
Tehle 1: Surrole statistics

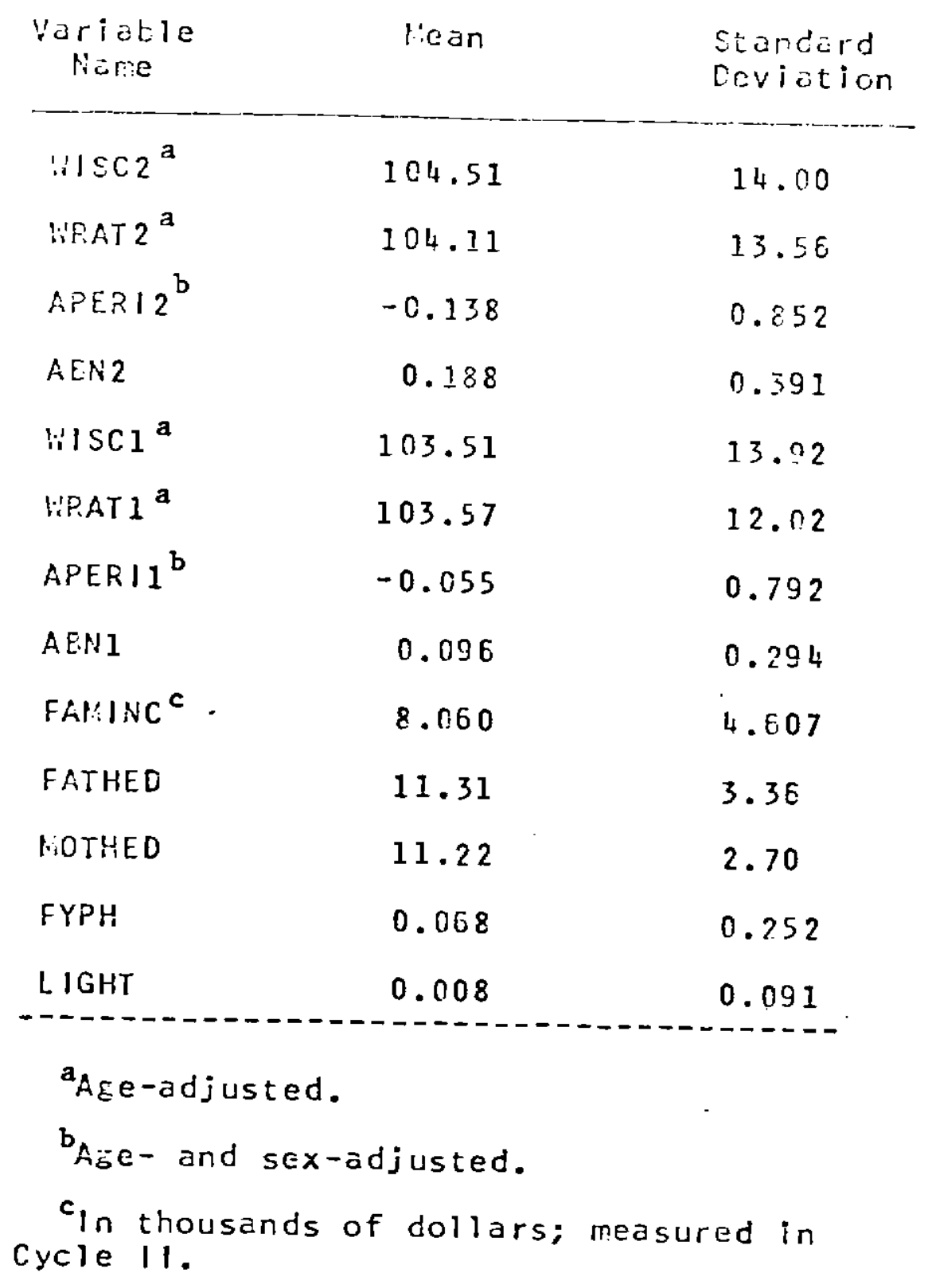


litcdels, while conceptually more desircatle, would add sulstantially to computational difficulty.

1/1. Estimates

The tasic lincar model (1) which is estinated consists of thirtcen equations. Each of the Cycle lll mastures of health and comitive develoment (IIISC2, HFAT2, AEn2, APERI2) is written as a I inear function of the health and cognitive development measures in Cycle II (b!ISC1, HRAT1, AEN1, APERI1), family income (FAPINC), and parents' education (FATHED, MOTHED). The four measures from Cycle II are written as linear functions of family income, parents' education, and initial health (FYPH, LIGHT). To complete the model, family income is presumed to depend on the education of each of the parents, and "first-year poor health" (FYPH) on low birth weight. Parents" education and low birth weight are not presumed to defend on any observable variable. It is apparent that this linear specification corresponds to restrictions on the elements of the matrix $B$ in (1).

To this specification of the structural links between observable variables is added different specifications of an unobserved factor structure. Estimates of two models are reported here. In the first, the factor space is presumed to be two-dimensional, with one factor operating in the health equations (AEN2, APERI2, ABN1, APERI2, FYPH, (IGHT) and the other operating in the cognitive development equations (HISC2, HRAT2, WISC1, HRAT1), each with equal effects in the equations determining income and parents' education (FAYllic, FATHED, (FOTHED). The factors are normalized to have unit variance, and il:e 
correlation betwcen the two factors is a parameter to be cetimated. The second specification presumes that observed variables alone determine $y$ (i.e. that $\Lambda=0$ in (1)). In the discussion following, this is referred to as the zero-factor model. In both the tro-factor and zero-factor specifications, the unsystematic stochastic effects in cach equation (the elements of the vector $\varepsilon$ in (I)) a re presuincd to be uncorrelated, except in the case of the two education equations. 9 This constrains the covariance matrix $\Sigma_{\varepsilon}$ to be nearly diagonal, with the one exception noted above. It can be verified that these implied restrictions are sufficient to identify all the unrestricted pararieters of (4).

To a large extent, the empirical focus of this paper is ex: : atory, so that the zero-factor model serves as a comparative henchmark. Tiwo empirical questions underlie the use of a model with unobserved factors: (1) can a model which takes account of such factors better explain the observed pattern of health and cornitive development? and (2) how do the estimates of such a model differ from those based solely on observed determinants?

The two specifications were estimated by maximizing (4) with respect to the unknown and unconstrained elements of $B, \Lambda, \Sigma_{f}$, and $\Sigma_{\varepsilon}$. Since $B$ is constrained to be triangular and $\Sigma_{E}$ nearly diagonal, tre estimates of the zero-factor model are equivalent to thcse obtained by estimating each structural equation in (1) by ols. This makes these estimates generally comparable to those reported in Edwards and Grossman (1978) and Shakotko, Edwards, and Grossman (1980), and it is casily verified that the estimates are very similar. 
Cire slould point out that the presence of dichotomeus variables in the vector $y$ violates the normality assumption implicit in the proposed likelihood function (4), so that maximization of (4) is a quasi-likelihood procedure. A correct likelihood specification to take account of the dichotomous variables, or a two-stage procedure such as that suggested by Heckman (1972a), would te methodologically superior, but the computational difficulties for this thirteen equation model make such techniques impractical.

Tables 2 and 3 present estimates of the matrix $B$ for the two-factor and zero-factor models. Table 4 presents the estinated matrix of factor loadings in the two-factor model. The remainder of this section summarizes the main results.

(a) Interactions Eetween Health and Cognitive Development

It was argued in Section 1 that the use of longitudinal data and the inclusion of Cycle 11 data in the cycle 111 equations is one way to assess the structural dependencies between measures of health and cognitive development. The underlying question is whether each temporal event (an event being a particular outcome for WISC, WRAT, APEPI, AEN) depends on previous events, or whether it is the result of an independent drawing from a particular distribution whose parameters depend on some set of observed and unotserved background variables. ${ }^{10}$ in terms of the estimates reported in Table 2, the coefficient on cach variable's own laged value is a measure of univariate dependence, or structural persistence, in each process. The coefficients on 
TAEIE 2

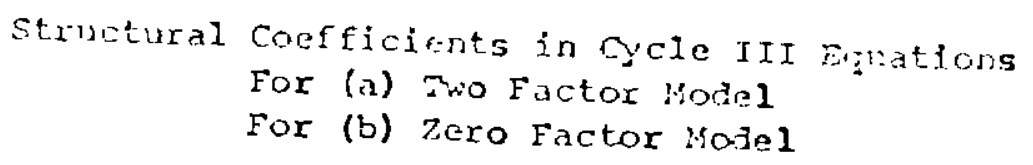

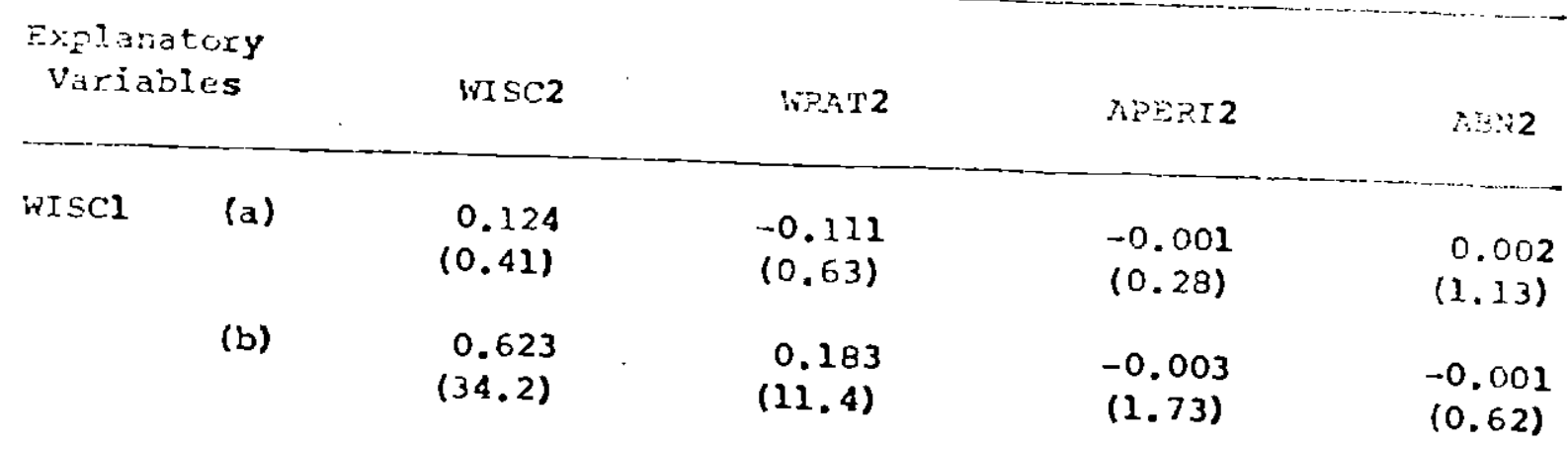

$\begin{array}{rrrrr}\text { (a) } & -0.094 & 0.565 & -0.005 & -0.001 \\ & (0.50) & (5.04) & (1.82) & (0.30) \\ & & & & \\ \text { (b) } & 0.215 & 0.746 & -0.006 & -0.003 \\ & (10.6) & (42.0) & (3.40) & (2.87)\end{array}$

\begin{tabular}{|c|c|c|c|c|c|}
\hline \multirow[t]{2}{*}{ APERI 1} & (a) & $\begin{array}{c}0.640 \\
(2.01)\end{array}$ & $\begin{array}{c}0.318 \\
(1.20)\end{array}$ & $\begin{array}{c}0.232 \\
(6.88)\end{array}$ & $\begin{array}{l}-0.042 \\
(1.42)\end{array}$ \\
\hline & (b) & $\begin{array}{c}0.316 \\
(1.11)\end{array}$ & $\begin{array}{c}0.127 \\
(0.51)\end{array}$ & $\begin{array}{r}- \\
0.269 \\
(10.3)\end{array}$ & $\begin{array}{r}0.009 \\
(0.72)\end{array}$ \\
\hline \multirow[t]{2}{*}{ בI = } & (a) & $\begin{array}{l}-0.345 \\
(0.42)\end{array}$ & $\begin{array}{c}0.491 \\
(0.71)\end{array}$ & $\begin{array}{l}-0.097 \\
(1.20)\end{array}$ & $\begin{array}{c}0.052 \\
(0.83)\end{array}$ \\
\hline & (b) & $\begin{array}{c}-0.996 \\
(1.32)\end{array}$ & $\begin{array}{c}0.108 \\
(0.16)\end{array}$ & $\begin{array}{c}-0.027 \\
(0.39)\end{array}$ & $\begin{array}{r}0.148 \\
(4.26)\end{array}$ \\
\hline \multirow[t]{2}{*}{ FAMINC } & (a) & $\begin{array}{c}-0.014 \\
(0.04)\end{array}$ & $\begin{array}{c}0.032 \\
(0.14)\end{array}$ & $\begin{array}{c}0.000 \\
(0.06)\end{array}$ & $\begin{array}{c}0.008 \\
(1.12)\end{array}$ \\
\hline & (b) & $\begin{array}{c}0.101 \\
(1.73)\end{array}$ & $\begin{array}{c}0.100 \\
(1.94)\end{array}$ & $\begin{array}{c}-0.002 \\
(0.45)\end{array}$ & $\begin{array}{c}0.004 \\
(1.64)\end{array}$ \\
\hline
\end{tabular}


TABLE 2 (concluaed)

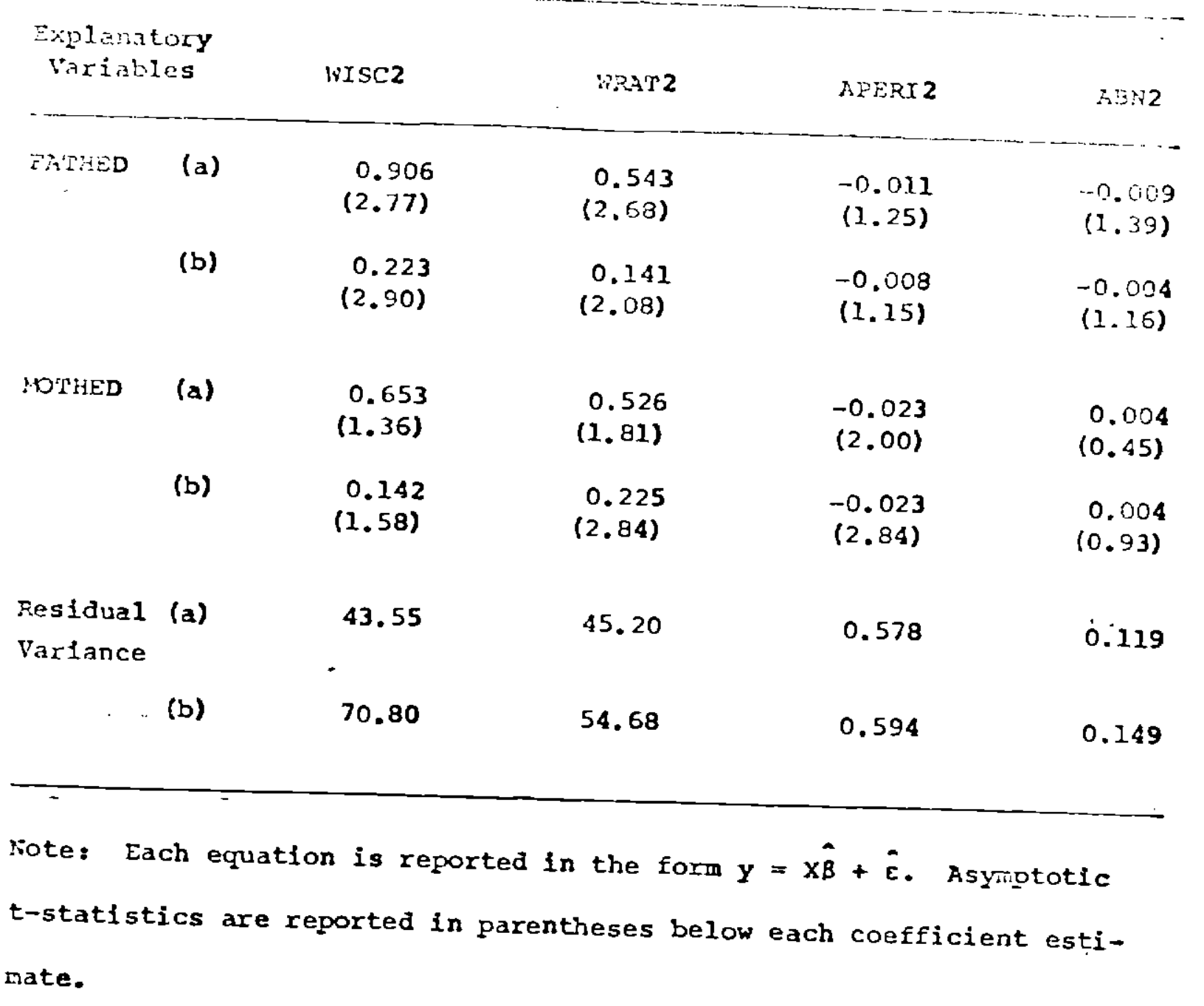


TATILE 3

Structural Coefficlents in Cycle II, Incoine, and Initial losith Exilations

For (a) Two Factor Nodel

For (b) zero Factor losel

\begin{tabular}{|c|c|c|c|c|c|c|c|}
\hline \multicolumn{2}{|c|}{$\begin{array}{l}\text { Explanatory } \\
\text { Variables }\end{array}$} & WISCl & WRATl & APERII & $A B N 1$ & FAWINC & FPH \\
\hline \multirow[t]{2}{*}{ EXUIIUC } & (a) & $\begin{array}{c}-0.062 \\
(0.17)\end{array}$ & $\begin{array}{l}-0.030 \\
(0.11)\end{array}$ & $\begin{array}{l}-0.004 \\
(0.42)\end{array}$ & $\begin{array}{c}0.001 \\
(0.24)\end{array}$ & - & - \\
\hline & $(b)$ & $\begin{array}{c}0.220 \\
(2.61)\end{array}$ & $\begin{array}{l}0.184 \\
(2.42)\end{array}$ & $\begin{array}{c}-0.009 \\
(1.67)\end{array}$ & $\begin{array}{c}-0.001 \\
(0.37)\end{array}$ & - & - \\
\hline \multirow[t]{2}{*}{ FATHED } & (a) & $\begin{array}{c}0.934 \\
(3.69)\end{array}$ & $\begin{array}{r}0.739 \\
(3.66)\end{array}$ & $\begin{array}{c}-0.019 \\
(2.01)\end{array}$ & $\begin{array}{c}0.002 \\
(0.71)\end{array}$ & $\begin{array}{c}0.528 \\
(12.8)\end{array}$ & - \\
\hline & (b) & $\begin{array}{c}0.946 \\
(8.91)\end{array}$ & $\begin{array}{r}0.748 \\
(7.84)\end{array}$ & $\begin{array}{c}-0.019 \\
(2.76)\end{array}$ & $\begin{array}{c}0.002 \\
(0.91)\end{array}$ & $\begin{array}{r}0.539 \\
(17.9)\end{array}$ & - \\
\hline \multirow[t]{2}{*}{ MOTHED } & (a) & $\begin{array}{c}0.914 \\
(1.97)\end{array}$ & $\begin{array}{c}0.519 \\
(1.49)\end{array}$ & $\begin{array}{l}-0.016 \\
(1.27)\end{array}$ & $\begin{array}{c}0.000 \\
(0.08)\end{array}$ & $\begin{array}{c}0.351 \\
(5.11)\end{array}$ & - \\
\hline & (b) & $\begin{array}{l}1.328 \\
(10.8)\end{array}$ & $\begin{array}{r}0.833 \\
(7.51)\end{array}$ & $\begin{array}{l}-0.024 \\
(3.09)\end{array}$ & $\begin{array}{l}-0.002 \\
(0.57)\end{array}$ & $\begin{array}{c}0.383 \\
(10.3)\end{array}$ & - \\
\hline \multirow[t]{2}{*}{ FYPH } & (a) & $\begin{array}{c}2.426 \\
(2.43)\end{array}$ & $\begin{array}{l}-0.247 \\
(0.20)\end{array}$ & $\begin{array}{l}-0.023 \\
(0.21)\end{array}$ & $\begin{array}{r}0.047 \\
(1.26)\end{array}$ & - & - \\
\hline & (b) & $\begin{array}{r}0.305 \\
(0.24)\end{array}$ & $\begin{array}{l}-1.854 \\
(1.62)\end{array}$ & $\begin{array}{c}0.124 \\
(1.52)\end{array}$ & $\begin{array}{l}0.085 \\
(2.75)\end{array}$ & - & - \\
\hline \multirow[t]{2}{*}{ LIGHT } & (a) & $\begin{array}{l}-5.046 \\
(1.94)\end{array}$ & $\begin{array}{l}-8.100 \\
(3.10)\end{array}$ & $\begin{array}{l}-0.042 \\
(0.18)\end{array}$ & $\begin{array}{l}-0.031 \\
(0.35)\end{array}$ & - & $\begin{array}{r}0.087 \\
(1.16)\end{array}$ \\
\hline & (b) & $\begin{array}{l}-8.602 \\
(2.43)\end{array}$ & $\begin{array}{l}-10.80 \\
(3.40)\end{array}$ & $\begin{array}{l}-0.013 \\
(0.06)\end{array}$ & $\begin{array}{c}-0.023 \\
(0.27)\end{array}$ & - & $\begin{array}{r}0.099 \\
(1.36)\end{array}$ \\
\hline \multirow[t]{2}{*}{ Vartance } & (a) & 52.85 & 64.99 & 0.570 & 0.084 & 14.29 & 0.061 \\
\hline & (b) & 148.30 & 119.79 & 0.604 & 0.086 & 14.55 & 0.064 \\
\hline
\end{tabular}

Note: Each equation is reported in the form $y=x \hat{B}+\hat{\varepsilon}$. Asyintotic t-statistics are reported in parentheses below each coefficient estiriate. 
other lakged variables measure dependence between processes.

Tlic estimated coefficients for the two-factor model (denoted by rows (a) in Table 2) indicate significant qualitative differences in the structural persistence of each of the four processes. HISC 2 and AEN2 do not depend significantly on WISCl and AENI respectively, While WRAT2 and APERI2 exhibit substantial dependence on LRAT1 and APERI1. It is not hard to rationalize at least this latter result. If URAT measures acquired skills, then it is not likely that these skills will disappear over a three- or four-year interval, so that current WRAT scores will reflect to a large extent past accumulation of skills, quite aside from whether this accumulation is related to other variables. Similarly, one might imagine that oral health is also persistent: decay or periodontal disease tends not to appear or disappear in a fairly short interval. WISC, on the other hand, purports to measure aptitudes or innate abilities. It is reasonable to argue that the score on one test should not depend on the score in a previous test, but that both scores reflect independent measurements of underlying individual-specific variables. ${ }^{11}$ It is interesting and puzzling, however, that there is not significant persistence in the AEN equation. The same argument used for the periodontal index might apply in the case of a diagnosed abnormality. It is noteworthy that this lack of persistence is also evident in the raw data, where the correlation between $A B N 1$ and $A B N 2$ is only 0.11 , so that the small coefficient on AENI may not be a statistically artifact.

The point estimates for the two-factor model indicate less structural persistence than corresponding estimates for the zero- 
factor nodel, also reported in Tatle 2 (and denoted ty rews (b)). Tlie inplication is that the observed serial correlation in health and cosnitive development is better explained by persistent underlyine factors tran persistence in the actual processes. This is exemined in sroater detail in section (c) bclow.

In Eeneral, the cstimated cross-effects tetween processes are small and not sienificant. This is found in toth tle two-factor and zero-factor models. Two exceptions should be noted. First, LISC and WRAT contribute positively to APERI2 in both models, although only WPAT is sisnificant in the APERI2 equation at the 90 percent level in the two-factor model. The effect is not very large, hovever: expressing the point estimate of -0.005 in terms of standard deviations, a one standard deviation increase in WRATl results in a 0.07 standard deviation improvement in APERI2.

The second exception is in the HISC equation, where high values of APERII (i.e. poor oral health) are associated with high WISC scores. Even though the magnitude of this effect is small (a one standard deviation change in APERII results in a 0.04 standard

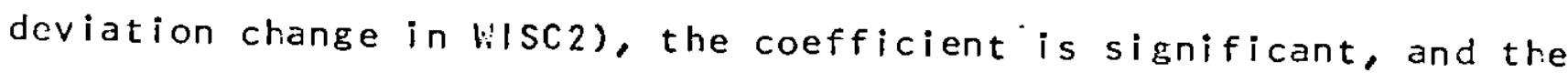
direction of the effect is contrary to what one might expect from a structural relationship. The coefficient may, however, reflect a substitution effect in a heterogeneous population, in the sense that some families may choose to make time and income investments directed toward health, and other families investments directed toward coinitive development of children. 
(b) Inccine and Education Effects

In all the equations roported in Tables 2 and 3, family incone is not a significant determining factor in the two-factor model. Tlis is in contrast to the estimates of the zero-factor model, where income has a significant positive effect on both bisc and VieAT. It should be noted, moreover, that in the tro-factor model, the point estimates of these and other income effects are substantially smaller than those in the zero-factor model, so that the insignificance does not arise totally from larger standard errors.

On the other hand, the two-factor model confirms many of the education effects in the zero-factor model, and in some cases, the Firit estimates are larger. In the WISC2 and WRAT2 equations, the effect of a marginal year of father's education increases from 0.223 to 0.906 and 0.141 to 0.543 respectively. Mother's education is less significant in these equations, but nevertheless, the point estimates show this same pattern of increase. The education estimates are generally significant and of the same order of magnitude in the WISCI and kRAT1 equations.

In the health equations, parents' education is significont in both APERI equations, although at marginal confidence levels. This is not the case in the $A B N$ equations, where neither the coefficients nor the confidence levels are large.

Two other equations linking observed variables were also est imated jointly with the cycles 11 and 111 health and cognitive development equations. In the first, family income was supposed to 
drepend on parents' education. It is found that a marginal ycar of father's crucation contributes on average $\$ 528$ and mother's education $\$ 351$. Evaluated at the mean level of income, these estimatcs imply rates of return of 6.5 and 4.5 percent respectively, which are ccmparable to other estimates of earnings functions. The second ecuation supposes that "first-year poor health" dcpends to solie extent on low birth weight. A positive effect is found in both models, but in neitlier case is it significant.

(c) Factor Loadings

A casual inspection of Table 4, which shows the estimated factor icidings in the tvio-factor model, suggests that a large part of the variance in health and cognitive development in children can be explained by common unobserved factors. This is especially evident in the cognitive development equations, where the positive point estimates (reported as Factor 1 in Table 4) indicate a factor contributing positively to WISC and WRAT. Squaring the ratio of the factor loading to the standard deviation of the corresponding dependent variable yields the proportion of variance explained by the factor. In the case of WISC, this proportion is about 53 percent in both Cycles 11 and 111 . In the case of WRAT, the proportion is 40 percent in Cycle 11 , and declines to 19 percent in Cycle III. This is perhaps indicative of the growing relative influence of other factors on WRAT in the course of the child's development.

The second common factor was constrained to operate in the health 
Factor Loadings and Resilual varlinces: Tro factor lojel

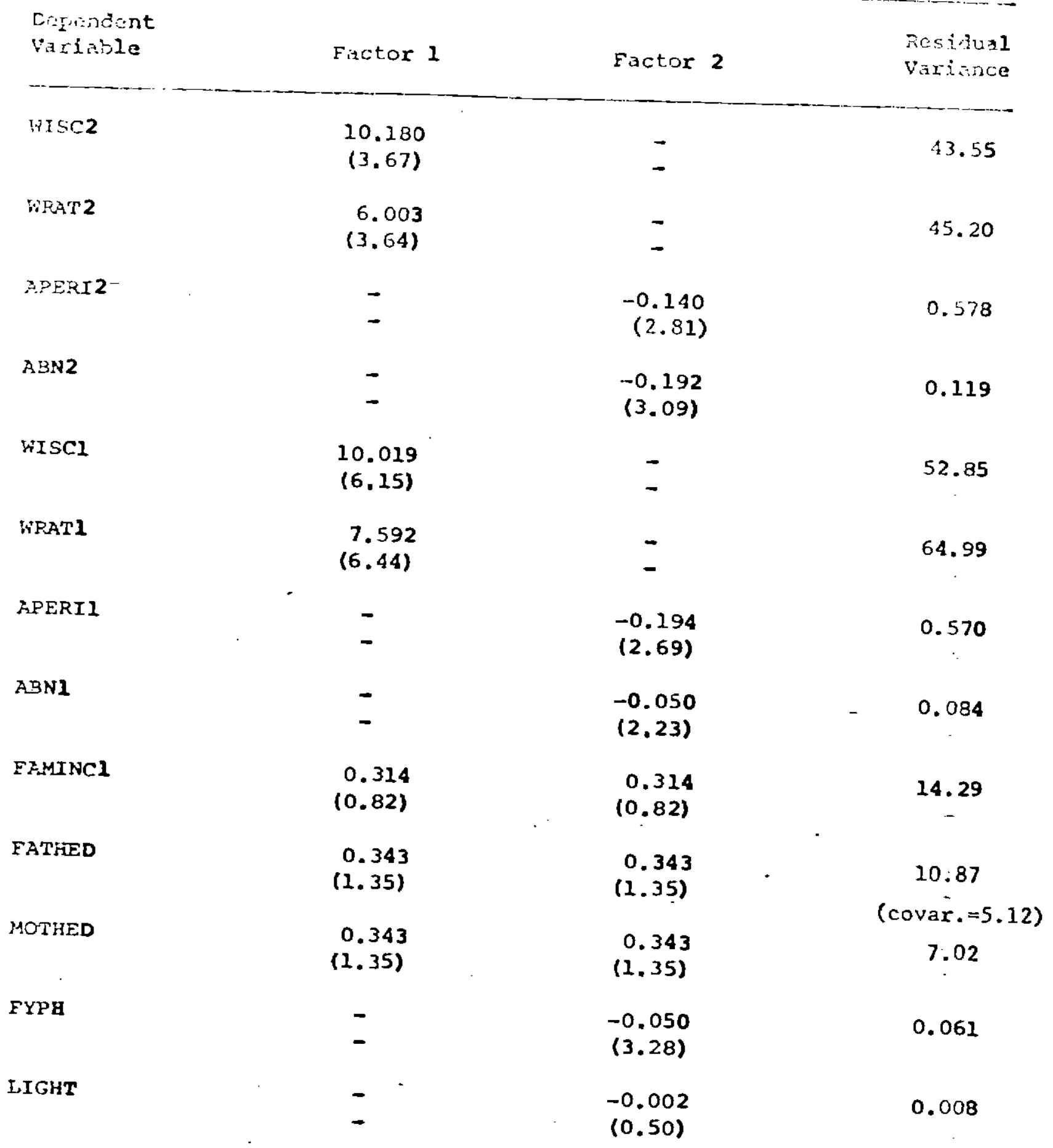

ERI 2- 2

Factors are normalized to have unit variances. The correlation betiraen the two factors was estinated at 0.397 (std. err. $=0.100$ ). Isymototic t-statistics are reported in parentheses below each coefficient. 
equations for cycles 11 and 111 , and in the cquaticns detcrmining FYPH and LIGHT (Factor 2 in Table 4). It cnters with a nogative sign in all hicalth equations, indicating a conmon positive contribution to health. The estimated loadings are significantly different from zoro in all except the LIGHT equation. The explanatory contribution of this health factor is not nearly so dramatic as that of the cognitive development factor discussed above. In the APERI cquations, 5 percent of the cycle II variance cen be attributed to the factor, and less than 3 percent in Cycle $\mid 11$, again indicative of growing environmental influence. In the AEN equations, this proportion is 3 percent in Cycle 11 , but grows to 25 percent in Cycle 111 . Approximately 4 percent of the FYPH variance was explained by the factor.

Eoth factors were presumed to be reflected equally in family income and parents' education. Being positive factors in the sense that they contribute to higher levels of WISC and WPAT and better health, one might expect that if these factors are generationally related, they should al so be positively related to income and education levels. The estimates confirm this expectation, although for neither income nor education are the estimated loadings significantly different from zero. This insignificance may reflect more of an attenuation in the factor conmunalities between parents and children than the absence of common factors in these "parents"" equations. Despite the insignificance, the point estimate for education is fairly large. One positive standard deviation in either factor is associated with 0.34 additional years of schooling for cech parcnt. 
Eesides the factor loadines, the correlation tetriecn tie tro factors vas cstimated. This correlation is estimated to te 0.397, With a standard error of 0.100 , indicating a significant positive relationship between the health and cognitive development factors.

One final issue should be addressed, namely that of the scodness-of-fit of each of the riodels. Under the assumption of normality, $-2 L(m a x)$ is distributed as $x^{2}(q)$, where $q=n(n+1) / 2-p$ and $p$ is tie number of parameters to be estinated, and were $n$ is tre number of equations. For the two-factor model, $x^{2}(10)$ vias estimated to be 18.29, which falls within the 90 percent confidence resion; this indicates that the null hypothesis of a two-factor model, toretrer With effects from observed variatles, cannot be rejected at the 90 percent level in explaining the observed relationships between health, cognitive development, and economic variatles. As a comparison, the $x^{2}$-statistic for the zero-factor model was over 100 , indicating that reliance on observable variables alone is not sufficient to satisfactorily explain the covariance structure of these variables.

It should be noted that a similar one-factor model was also estimated; the estimates, which are not reported here, vere very close to those of the two-factor model, and indeed many of the standard errors were reduced. The $x^{2}$-statistic for this model (with 14 d.f.) was estimated at 29.94, which does not fall within the 99 percent confidence region. In any case, it suggests that the two-factor estimates, and particularly those which relate observed variables, are fairly robust with respect to specification of the factor structure. 
IV. Conclusions and Implications

This andysis has shown that the introduction of motserved factors into an cmpirical model explaining chaildren's health and coinitive development adds considerably more explanatory power to such models. More notably, some findines from previcus empirical models are confirmed and strengthened, and other findings rejected. The sienificant results from the policy-makers noint of vicw conter on the effects of parents' education and family income. Parents' education is a significant positive contributor to cognitive development and oral health. No significant relationship was found tetween parents' education and diagnosed abnormalities. Contrary to other studies, income was found to play an insignificant role in both the health and cognitive development processes.

The implication is that an incomes' policy will not have a net impact on children's development. What cannot be distinguished here, of course, is whether increased income has both beneficial and detrimental effects which may be offsetting. As such, an incomes' policy combined with other programs may yield net benefits.

While the model considered here is limited in its consideration of explanatory and explained variatles, and while the statistical methodology is second-best in that it makes imperfect normality assumptions, the general techniques seem worthy of future investigation with other data and other measures of health. 



\section{Footnotes}

1. Grossman (1976) surveys the relationships among farnings, schooling, health, and measured intellitiche of adults and children that have been extensively discussed in rerent

2. See, for example, Eecker and Tomes (1976) and Ininan (1976).

3. See Kamin (1974) for a survey of the issucs and argulicnts that relate to the interitance of mental faculties.

4. A more detailed discussion of the hypothetical links betwen health and cognitive development can be found in Shalotko, Edvards, and Grossman (1980).

5. This model is a member of the class of structural equation models proposed by Joreskog (1973), who discusses more Eeneral forms of such models and aspects of the identification problem. A computer program to estimate models of this sort, and wich was used for this analysis, is described by joreskog and
Sorbom (1978).

6. Low values of APERI indicate better oral health.

i. A dumy variable was used instead of a continuous measure of birth weight since it is likely that the relationship between birth weight and poor subsequent health is non-linear.

8. Of course, the dichotomous nature of ABN precludes measurement of the severity of these conditions. A more rigorous specification of health would use a combination of ABN and a severity index or else an indicator vector of different health conditions.

9. Quite aside from any considerations in this model, a theory of matching would predict that spouses' education levels are positively correlated. To purge this effect from the model, a non-zero covariance between the stochastic effects in the iance is reported in Table 4 . An estimate of this covar-

10. This is in essence the issue at stake in the analysis of state dependence that has been used by Heckman (1978b) to study the time profile of labor force participation.

11. This independence might not be preserved if individuals "learned" how to take and score well on tests in the process of re-testing. 
References

Eccker, Gary S., and Tomes, Nigel, 1976. "Child Endorments and the Quentity and Quality of Children." Journal of Political Eccnomy 84 (4) : S143-S162.

Chamberlain, Gary, 1977. "Education, Incone, and Ability Revisited." Journal of Econometrics 5 (2): 241-257.

Chanterlain, Gary, 1978. "Omitted Variable Bias in Parel Cata: Estimating the Returns to Sctcoling." In The Econoretrics of Panel Data, Annales de l'insee 30-31:49-82.

Edwards, Linda N. and Grossman, Mictael, 1978. "Children's l'ealth and the Family." National Eureau of Economic Research, Working Paper No. 256.

Grossman, lichael, 1972. The Eemand for llealth: A Theoretical and Empirical Investigation. New York: Columtia Lniversity Press for the National Bureau of Economic Research.

Grossman, Fichael, 1976. "The Correlation Between Health and Schooling." In Houselold Production and Consumption, edited by N. E. Terleckyj. New York: Columbia University Press for the llational Eureau of Economic Research.

Grossman, Hictael, and Eenham, Lee, 1974. "Health, Hours, and Hages." In The Economics of Health and riedical Care, edited by rark Perlman. London: Macmillian.

Heckman, James J.: 1978a. "Dummy Endogenous Variables in a Simultaneous Equation System." Econometrica 46 (4): $931-959$.

Heckman, James J., 1978b. "New Evidence on the Dynamics of Female Lator Supply." University of Chicago, mimeo.

Inman, Robert $P_{:}$, 1976. "The Family Provision of Children's Health: An Economic Analysis." In The Role of Health Insurance in the Health Services Sector, edited by R. Rosett. Nen York: Columbia University Press for the National Eureau of Economic Research.

Joreskog, K., 1973. "A General Nethod for Estimating a Linear Structural Equation System." In Structural Equation Rodels in the Social Sciences, edited by A. S. Goldterger and 0 . 0 . Duncan. New York: Seminar Press.

Joreskog, K., and Sortom, D., 1978. LISREL-IV. Estimation of Linear Structural Equation systems by l'aximum Likel ihood Netrods: A FORTPAN-IV Program. Chicago: International Educational Services. 
ramin, Lcon J., 1974. The Scicnce and Politics of 10. How rork: Jolin liiley and sons.

Lee, Lung-Fei, 1979. "Health and liage: A simultancous Equation Approach." University of Minncsota, mimeo.

Slakotko, Rotert A., 1979. "State Dependence Eetween Asscts and Health." Columtia University, Lepartment of Economics, Discussion faper Ho. 78-7901.

Shakotko, Fotert A., Edvards, Linda N., and Grossman, Ricliael, 1980. "An Exploration of the Dynamic Rélationstip Eetween Heaith and Cognitive Development in Childhood." National Fureau of Eccnomic Research, mimeo. 